\title{
A New Hybrid Metaheuristic Algorithm for Wind Farm Micrositing
}

\author{
SHAFIQ-UR-REHMAN MASSAN*, ASIM IMDAD WAGAN**, AND MUHAMMAD MUJTABA SHAIKH*** \\ RECEIVED ON 25.07.2016 ACCEPTED ON 21.02.2017
}

\begin{abstract}
This work focuses on proposing a new algorithm, referred as HMA (Hybrid Metaheuristic Algorithm) for the solution of the WTO (Wind Turbine Optimization) problem. It is well documented that turbines located behind one another face a power loss due to the obstruction of the wind due to wake loss. It is required to reduce this wake loss by the effective placement of turbines using a new HMA. This HMA is derived from the two basic algorithms i.e. DEA (Differential Evolution Algorithm) and the FA (Firefly Algorithm). The function of optimization is undertaken on the N.O. Jensen model. The blending of DEA and FA into HMA are discussed and the new algorithm HMA is implemented maximize power and minimize the cost in a WTO problem. The results by HMA have been compared with GA (Genetic Algorithm) used in some previous studies. The successfully calculated total power produced and cost per unit turbine for a wind farm by using HMA and its comparison with past approaches using single algorithms have shown that there is a significant advantage of using the HMA as compared to the use of single algorithms. The first time implementation of a new algorithm by blending two single algorithms is a significant step towards learning the behavior of algorithms and their added advantages by using them together.
\end{abstract}

Key Words: Wind Farm, Jensen Wake Model, Nature Inspired Algorithms, Differential Evolution Algorithm, Firefly algorithm, Genetic Algorithm, Hybrid Meta-Heuristic Algorithm.

\section{INTRODUCTION}

$\mathrm{T}$ e topic of wind turbine micrositing has gathered a lot of attention internationally due to the rapid increase in the installation of wind power. It has been discussed in earlier literature that the wind turbine positioning can be improved by the use of the FA [1]. The goal of this work is to find a new method of solving the WTO problem. This solution examines the feasibility of using a multi-Algorithmic approach for the multi objective optimization is achieved.

Wind turbine micrositing is a complex problem of optimization because of the fact that it cannot be solved by exact methods. The problem space is non-linear and totally dependent on the complex interactions of the turbines installed with respect to the interaction of the wakes and the energy captured from them [2].

Producing power from a limited space of ( $2 \times 2 \mathrm{~km}$ area) is the main concern of this work. In this study the wind conditions are unchanged at $12 \mathrm{~m} / \mathrm{s}$ from the eastern side of the wind farm. The best or optimal condition is obtained with the results showing the number of turbines and the gathered power from those turbines with the efficiency of the power output. Reference is made to the past approaches that have used only one algorithm for achieving the same purpose [2-3].

* ShaheedZulfiqar Ali Bhutto Institute of Science \& Technology, Karachi.

** Mohammad Ali Jinnah University, Karachi.

*** Department of Basic Sciences \& Related Studies, Mehran University of Engineering \& Technology, Jamshoro.

Mehran University Research Journal of Engineering \& Technology, Volume 36, No. 3, July, 2017 [p-ISSN: 0254-7821, e-ISSN: 2413-7219] 
The main objective of this work is to propose a HMA for advancing the purpose of research in this field. This HMA is the combination of a mainstream algorithm the DEA and recent algorithm, namely the FA. Both algorithms are selected on the basis of their relative strengths. The DEA is known for escaping local optima and the FA is well known for its fast processing and efficient operation.

The method of nesting two algorithms is well known in literature and there are a number of publications available [4-5]. Other implementation are of HMAs are such as a combination of two or more algorithms to attain a common objective are also discussed in [6-9]. During the development of the metaheuristic algorithm the major limitations of both the algorithms in use were mapped and compared. The main objective was to get the maximum power at the lowest cost.

This study focuses on the recent interest during the midst of 2015 from the optimization community in the use of HMAs for the solution of engineering problems. The WTO problem has moved on to other avenues since then and has become a multi-dimensional topic by the application of the CFD (Computational Fluid Dynamics) approach [10-12].

The program code for optimization is developed in Matlab and run on a Core i3 computer with 8 GB RAM.

\section{LITERATURE REVIEW}

The area of wind farm optimization was pioneered by several authors including Mosetti, Beyer, Barthelmieand Grady [13-16]. In their approaches the solution space was encoded into a square grid of 2x2 km to facilitate the search string. They used the GA (Genetic Algorithm) primarily for achieving this purpose. There was added interest by the use of metaheuristic algorithms and the Jensen Model as deployed by Wan et. al. [17] and Marmidis et. al. 18].

Other authors such as Acero and Kusiak used other metaheuristic techniques such as Virtual Gene Algorithm, Markov Chain methods and Simulated Annealing [19-20].
Interestingly the work for WTO by using CFD domain was initiated very early by Palma et. al. [21]. It was also reported that the CFD is a more accurate method of micrositing during its infancy.

Then Wan et. al. [22] utilized the GA to arrive at systematic results for the simulation of the wind farm. His work was based on Grady et. al. [16] results.

This was followed by Emami and Nougreh [23] who advanced the work by considering the three scenarios, uniform and unidirectional wind, uniform and multidirectional wind and non-uniform and multidirectional wind. However his results were based on less strenuous parameters.

Moreover, Rasuo and Bengin [24] presented his work based on the GA. He was quick to note that the realistic wake effects can only be mapped by the use of a viscous flow model such as a CFD model. However, he realized that the computational cost of using both CFD and GA would be great.

The work of Lazarou et. al. [25] utilized the Powell's optimization method to reach similar results to the results obtained by Mosetti et. al. [13], Grady et. al. [16] and Marmidis et. al. [18].

Mora et. al. [26], used an evolutive algorithm and a global wind farm cost model to evaluate the results of wind farm optimization for three test cases.

Then Gonzalez et. al. [27] summed up the work done in this field in a review paper. The results were compared with Grady et. al. [16] and were an extension of the work of Mosetti et. al. [13].

This present work has evolved from the work of Mittal [3]. The work of Rajper [2] builds on the work of Mittal [3]. Much work has been done in the field of metaheuristics since the term was coined by Glover [28].

Other researchers contributed by adopting different approaches. Karampelas et. al. [29], utilized the downhill simplex optimization method to reach at the optimal number of wind turbines and the least cost of installing these turbines. 
Then, Villarreal and Espiritu [30], compared the results of Mosetti et. al. [13] by using a viral based algorithm. Addition to this field was made by Chowdhry et. al. [31] who used a miniature wind farm in conjunction with the PSO (Particle Swarm Optimization) Algorithm. A key aspect of this study was that the use of different rotor sizes were used in the same wind farm to obtain better simulation results.

Particle flow simulation or the use of CFD was added to this field by Song et. al. [32] who showed that the results of CFD were better than widely used linear model given by Jensen [33]. Again, Song et. al. [34], utilized the particle flow simulation method in conjunction with Greedy Algorithm.

Rahmani et. al. [35], compared his results with Mosetti et. al. [13] and Marmidis et. al. [18] by utilizing the PSO Algorithm.

Chen et. al. [36], used the Jensen model [33] in conjunction with nested GA for the improvement of results in a wind farm. He used two different heights for wind turbines in his study.

Gaumond et. al. [37], investigated the three main wind models while applied to an actual wind farm and concluded that the wake models were under-predicting the power produced.

A good formulation of the optimization problem has been discussed in [9]. Moreover a wide number of applications of hybrid algorithms have been illustrated in literature these include [38-45].

Rao and Shyju [38], used a HMA known as the MSGNS (Multiple-Start Guided Neighborhood Search Algorithm). This algorithm was comprised of the two popular, Tabu Search and Simulated Annealing algorithms. Rao and Shyju [38] proposed a better solution to the laminate composite structures used in Aerospace. The results demonstrated superiority over the use of popular algorithms, when used alone, such as simulated annealing and GAs.
Salcedo-Sanz et. al. [39] used the HMA approach for the solution of the task assignment problem in Heterogenous Computing applications.

Shahsavari-Pour and Ghasemishabankareh [40], solved the FJSP (Flexible Job-Shop Scheduling Problem) by the use of novel HMA- NHGASA. He utilized three objective functions that minimized the total time of the operations, minimized the load on the most used machine and minimized the load on all the machines. His approach produced better results than classical results reported in literature.

Lozano and García-Martínez [41], proposed the combination of two algorithms, the ILSA (Iterative Local Search Algorithm) and an Evolutive Algorithm. These algorithms were used to reach better values of the parameters of intensification and diversification.

Leung et. al. [42], utilized the HMA for the solution of the knapsack packing problem. He utilized the Simulated Annealing and a greedy strategy for the solution of this problem.

Poorzahedy and Rouhani [43], was able to use a HMA for solving the network congestion problem by the use of GA, Simulated Annealing and Tabu Search. The results were better than the Ant Colony Optimization Algorithm.

Yi et. al. [44], proposed three HMAs for Engineering design optimization. His results were better than the Hybrid Differential Evolution Algorithms.

Fattahi et. al. [45], compared several Pareto based inventory control models by the use of HMA in his work.

A recent publication Massan, et. al. [46] may also be referenced for the application of the Differential Evolution Algorithm in this domain.

There are two main papers that have discussed the use of bi-algorithmic approach for wind farm optimization these are [4-5]. In these papers Wan et. al. [4-5] has proposed a similar approach to our research. Wan has used PSO algorithm along with Gaussian mutations (GPSO) to solve the constrained optimization problem. 
Wan et. al. [5] has proposed that the global optimization and local optimization is reached by the use of two Gaussian mutation operators. The first Gaussian operator finds the global best solution while the local operator searches in the vicinity of the global best solution. In such a scenario, the local optima is efficiently searched by two levels of operation. It is widely known that GPSO is efficient and robust for finding the global optima and the simulation results show that there is a wide improvement in using the two operators [4-5].

\section{MATERIALS AND METHOD}

\subsection{Wind Farm Model}

The wake model used shall be the Jensen model [33] as it gives the two constraints of optimization i.e.

(1) The power generated in terms of the wind speed

(2) The cost model

The same assumptions are taken as in previous studies [1-3],
Hub height $=60 \mathrm{~m}$

Rotor radius $=40 \mathrm{~m}$

Thrust coefficient $=0.88$

Fig. 1 illustrates the model.

In such layouts, each grid point has its own wind speed denoted by $\mathrm{u}_{\mathrm{i}}$ when this wind speed interacts with a wind turbine wake appears. This wake expands in a linear fashion behind the wind turbine in the wind direction. The wake expansion is given by the factor á that is derived from the hub height $\mathrm{z}$ and the terrain roughness $\mathrm{z}_{0}$.

The computer program shall be run so that multiple wakes are accounted for as well as the exact terrain roughness of that point.

The listed variables were utilized in the Matlab program, $r_{r}=$ Turbine rotor radius which is the radius of the wake $\mathrm{X}=$ The distance at which the wake is calculated $\mathrm{r}_{1}=$ The radius of the wake at distance $\mathrm{X}$

According to Betz's theory [47] the wind speed after the rotor is given by:

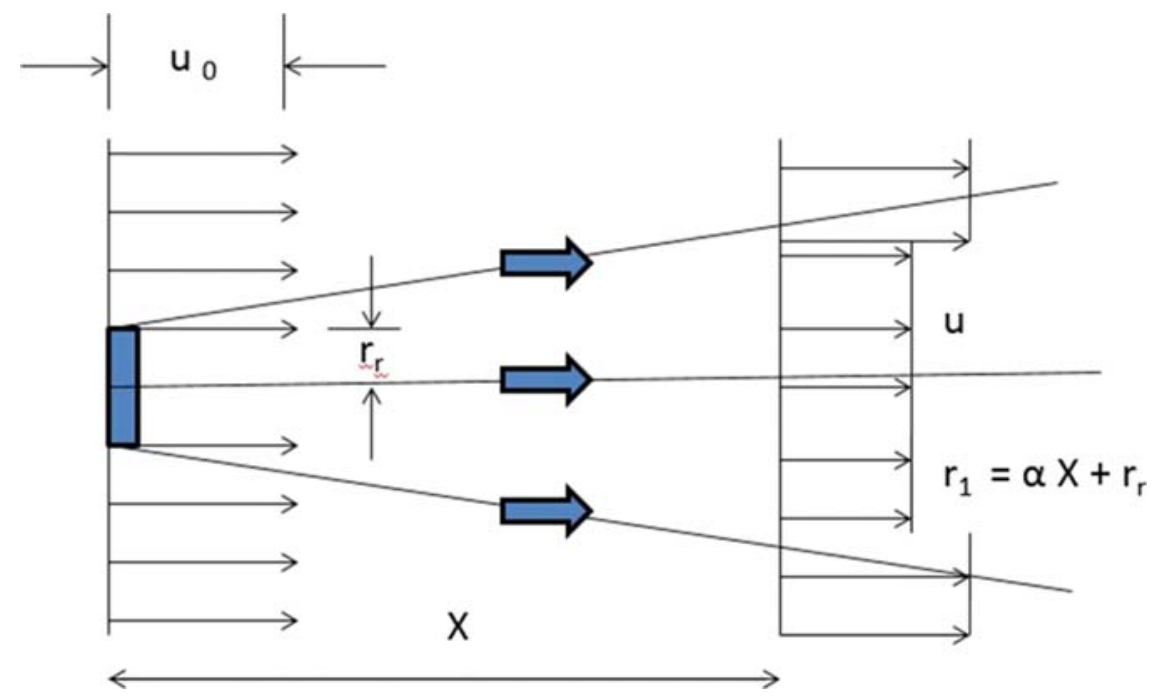

FIG. 1. THE WAKE MODEL SCHEMATIC 
$U=u_{0}+\left(1-\frac{2 a}{1+\alpha \frac{x}{r 1}}\right)$

Thus a value of $U$ is obtained. Moreover, from [48] the axial induction factor $a$ is derived from the Thrust Coefficient $\mathrm{C}_{\mathrm{T}}$ as follows

$\mathrm{C}_{\mathrm{T}}=4 \mathrm{a}(1-\mathrm{a})$

We may now write $r_{1}$ as related to $r_{r}$ as:

$r_{1}=r_{r}^{2} \sqrt{\left(\frac{1-2}{1+2 a}\right)}$

Where as, from [33] the calculation of the entertainment constant á is done for every grid point as follows:

$\alpha=\frac{0.5}{\ln \left(\frac{z}{z_{0}}\right)}$

Where hub height $\mathrm{z}=60 \mathrm{~m}$ and the value of the terrain of $\mathrm{z}_{\mathrm{i}}$ at the grid point yields the á for that point [9] It may be remarked that the lesser the $\mathrm{z}_{0}$ the narrow the wake [9].

The equation for multiple wakes is denoted by:

$u_{i}=u_{0}+\sum_{i=1}^{N_{t}}\left(1-\frac{u}{u_{0}}\right)$

Where the available power can be calculated from equation:

Available Power $=\frac{1}{2} \rho \mathrm{Au}^{3}$

With the addition of efficiency the equation becomes:

Available Power $=\eta \frac{1}{2} \rho A u^{3}$

The power produced is reduced to
Power ProducedP(n) $=0.3 \mathrm{u}^{3}$ Kilowatts

The efficiency is given by the following equation:

Available $\eta=\frac{\sum_{\mathrm{i}-1}^{\mathrm{N}_{\mathrm{t}}} 0.3 \times \mathrm{u}_{\mathrm{i}}^{3}}{\mathrm{Nt}\left(0.3 \times \mathrm{u}_{\mathrm{i}}^{3}\right)}$

or

$$
\text { Available }=\frac{\text { Power }_{\text {Total }}}{\mathrm{Nt}\left(0.3 \times \mathrm{u}_{\mathrm{i}}^{3}\right)}
$$

\section{Cost Model}

The cost model is generic and is given in literature as follows:

$\operatorname{Cost} C(n)=N_{t}\left(\frac{2}{3}+\frac{1 e^{-0.00174} N_{t}}{3}\right)$

Where $\mathrm{N}_{\mathrm{t}}$ is the number of turbines [5].

\subsection{The Optimization Problem}

It is known that, a population of solutions to the optimization problem can be generated with $\mathrm{k}$ population:

Solution $=\left[\mathrm{x}_{1}, \mathrm{x}_{2}, \mathrm{x}_{3}, \ldots, \mathrm{x}_{\mathrm{n}}, \ldots, \mathrm{x}_{\mathrm{k}}\right]$

The bi-objective (cost and power) fitness values for the optimization problem at any instant, can be written as:

$\left\{\begin{array}{l}\operatorname{Max} P(n) \\ \operatorname{Min} P(n)\end{array}\right.$

Where $P(n)$ and $C(n)$ are values of power and cost of the wind farm at a certain instant in the iterative process. 
Where,

Power Produced, $\mathrm{P}(\mathrm{n})$ is taken from Equation (8) and the Cost, C(n) from Equation (11). The optimization problem Equation (12) is subject to the constraints that:

$$
\left\{\begin{array}{c}
0 \leq \mathrm{x}_{\mathrm{i}} \leq \mathrm{W} \\
0 \leq \mathrm{y}_{\mathrm{i}} \leq \mathrm{L} \\
0 \leq 2 \sqrt{\left(\mathrm{x}_{2}-\mathrm{x}_{1}\right)^{2}-\left(\mathrm{y}_{2}-\mathrm{y}_{1}\right)^{2}}-\mathrm{D}^{2}
\end{array}\right.
$$

Where, $\mathrm{L}$ is the length and $\mathrm{W}$ is the width of the wind farm and $\mathrm{D}$ is the minimum distance between two adjacent wind turbines.

\subsection{The Differential Evolution Algorithm}

The DEA is an Evolutionary Algorithm that is related to Stochastic Search Algorithms. This algorithm searches a known domain for a global maxima or a minima. It is similar to GA, PSO Algorithm and the Evolutionary Strategy Algorithm as well as Evolutionary Programming Algorithms [49-50].

The DEA is similar to the GAs as it utilizes the main processes of selection-evaluation-recombination. This algorithm is outstanding as it adds a new dimension by looking for unique solutions by the process of recombination [51]. The process of recombination is facilitated by the addition of new species that are a result of a weighted difference of two old members that are recombined with the third member [50].

However, it has been found from the algorithm implementation that it is computationally expensive and nimble fine tuning of the parameters is required for better implementation [51].

\subsection{The Firefly Algorithm}

This algorithm is good at evaluating a cost or objective function under many constraints and the problem can either be linear or non-linear [27-28]. It functions in the stochastic domain which means that several solutions to the same problem may exist. However, if we sufficiently increase the number of iterations the problem may succumb to a single global solution set (Global minima or global maxima).

The basic working of the algorithm is very simple to understand. It mimics the mating behavior of Fireflies with the given sets of assumptions [27-28].

(1) All fireflies are equally attracted to each other which means there is a single gender.

(2) Brighter fireflies are more attractive. In this case the permeability of the medium may be altered to configure the algorithm properly. In the case of a tie i.e. if two fireflies have the same brightness then they shall move independently.

(3) The objective/cost function determines how bright a firefly is, therefore, in other words the main function of the algorithm is served here.

This algorithm investigates the complex nature of the interaction of the brightness as compared to the attractiveness between the individual fireflies. The objective function shows the strength of the wind which is useful for calculating the cost as well as the attractiveness of the fireflies. The objective function is responsible for determining the distance between adjoining fireflies [27].

The FA is more suitable for due to its simplicity and simple coding. It is useful for optimization problems as it mimics the intensity of the brightness that results in maximization of the objective function [1,46-48].

\section{Firefly Algorithm (Mathematical Model)}

The inverse square law gives the light intensity:

$\mathrm{I}=\mathrm{I}_{0} \mathrm{e}^{-\gamma r}$

Giventhat:

$\mathrm{I}(\mathrm{r})$ is light intensity,ris Distance, $\mathrm{I}_{0}$ is Original light intensity,and $\gamma$ is Light absorption coefficient. 
The objective function can be interchangeably used to denote the intensity of light of a firefly and attractiveness of one firefly to another. Both these terms are interchangeable and are dependent on the objective function [27-28]. In view of the above, if we replace the attractiveness with its proportional counterpart; intensity then

$\beta=\beta_{0} \mathrm{e}^{-\gamma 2}$

The equation may be modified, as in [53],to read as follows:

$\beta(r)=\beta_{0} \mathrm{e}^{-\gamma \mathrm{m}}(\mathrm{m}>1)$

Moreover, the Cartesian distance existing between two fireflies $i$ and $j$ at $x_{i}$ and at $x_{i}$ is governed by the following equation, as in [52,55-56].

$\mathrm{r}_{\mathrm{ij}}=\left\|\mathrm{x}_{\mathrm{i}}-\mathrm{x}_{\mathrm{j}}\right\|=\sqrt{\sum_{\mathrm{k}=1}^{\mathrm{d}}\left(\mathrm{x}_{\mathrm{i}, \mathrm{k}}-\mathrm{x}_{\mathrm{j}, \mathrm{k}}\right)^{2}}$

The term, $x_{i k}$ defines the $k$ th value of the $x_{i}$ of the $i^{\text {th }}$ firefly.

The attractiveness of the $i^{\text {th }}$ and the $j^{\text {th }}$ fireflies results in the movement that is governed by the following equation:

$\mathrm{X}_{\mathrm{i}}=\mathrm{X}_{\mathrm{i}}+\beta 0 \mathrm{e}^{-\gamma 2}\left(\mathrm{X}_{\mathrm{i}}-\mathrm{X}_{\mathrm{i}}\right)+\alpha \varepsilon_{\mathrm{j}}$

In the above equation $\mathrm{x}_{\mathrm{i}}$ and $\mathrm{xj}$ are just positions the second term is the attraction between the two and the last term gives the randomness factor in the above guess.

\subsection{Meta-Heuristic Algorithm Implementation Methodology}

The MHA has the intelligence to explore the search space effectively and not miss any points of the local optima. At the global scale it is ingenious at escaping the local minima and astute enough to intensify the density of the turbines at high wind areas [57].

The proposed bi-algorithmic approach uses the two mainstream algorithms namely

(1) The Differential Evolution Algorithm

(2) The Firefly Algorithm
The working of the solution is discussed briefly as follows:

A map of the region is taken and divided into (100x100) grid points. However, the DEA is allowed to work in a solution space of only $(99.5 \times 99.5)$ grid points. This is because the FA is allowed to function in $(0.5 \times 0.5)$ grid points. The resultant map can be used to identify the boundary and non-boundary regions of the solution set.

Then the HMA is run on the solution space in which the DEA is executed first to find the global optimization on $\mathrm{n}^{2}$ area. In our present calculations a base/model area of (99.5x99.5) grid spaces in a $9900.25 \mathrm{~km}^{2}$ area. The remaining space of $0.5 \times 0.5$ grid spaces is covered by the FA.

The HMAs does the initial calculations on the basis of the DEA and then does the Local Optimization automatically by the application of FA for each turbine position to find the best solution.

Thus, with the application of the two algorithms the global best solution can be enhanced by any scalar amount to become the global as well as local best position. Therefore, both algorithms working together in tandem can yield a better solution set in a piecewise manner.

The parameters of concern in the DEA are population size which is taken as 500 and the maximum time for the iteration which is taken as 900 seconds. Whereas the parameters of concern in the FA are taken as number of fireflies were taken as 20, Number of iterations were 100, Alpha was 0.5, Beta ${ }_{\min }$ was 0.2 and Gamma was 1.

\section{RESULTS AND DISCUSSION}

Fig. 2 gives a comparison of the power produced by the HMA as compared to the GA [2].

After the simulation was run it was noticed that the results of HMA were better for higher number of turbines as compared to the GA. Only for 10, 16, 17, 18 and 19 turbines the results of GA [2] were better.

It was seen that HMA reported the same results for Power till the $9^{\text {th }}$ turbine was installed. At the installation of the $10^{\text {th }}$ turbine the HMA reported a value of 5183.99 
$\mathrm{kW}$ for power whereas the GA [2] reported a value of $5184.00 \mathrm{~kW}$.

It was also noticed that the Power obtained by using the HMA is measurably higher per unit turbine installed after the installation of the twentieth turbine.

The power difference is evident when the $20^{\text {th }}$ turbine is installed where by HMA we got a resultant power of $10,361.76 \mathrm{~kW}$ but with GA a lower value of 10,351.68 kW is obtained. This trend continues till the installation of the $100^{\text {th }}$ turbine where the HMA reports a higher amount of power produced of 50,846.92 as compared to the GA at $48,452.26 \mathrm{~kW}$.
Fig. 3 discussed below compares the dimensionless cost by the use of the HMA as compared to the standard GA as used by [2].

The total cost per unit turbine for the HMA is better as compared to the GA [2]. The only exception to the supremacy of the HMA is for turbine numbers 16, 17, 18 and 19 where the GA [2] reports better results.

At the installation of the $16^{\text {th }}$ turbine the GA [2] reports a result of 0.0016979 and the HMA lags slightly behind at 0.001698. This trend continues till the installation of the $19^{\text {th }}$ turbine where the GA [2] reports a result of 0.0016291 and the HMA lags behind at 0.0016298 .

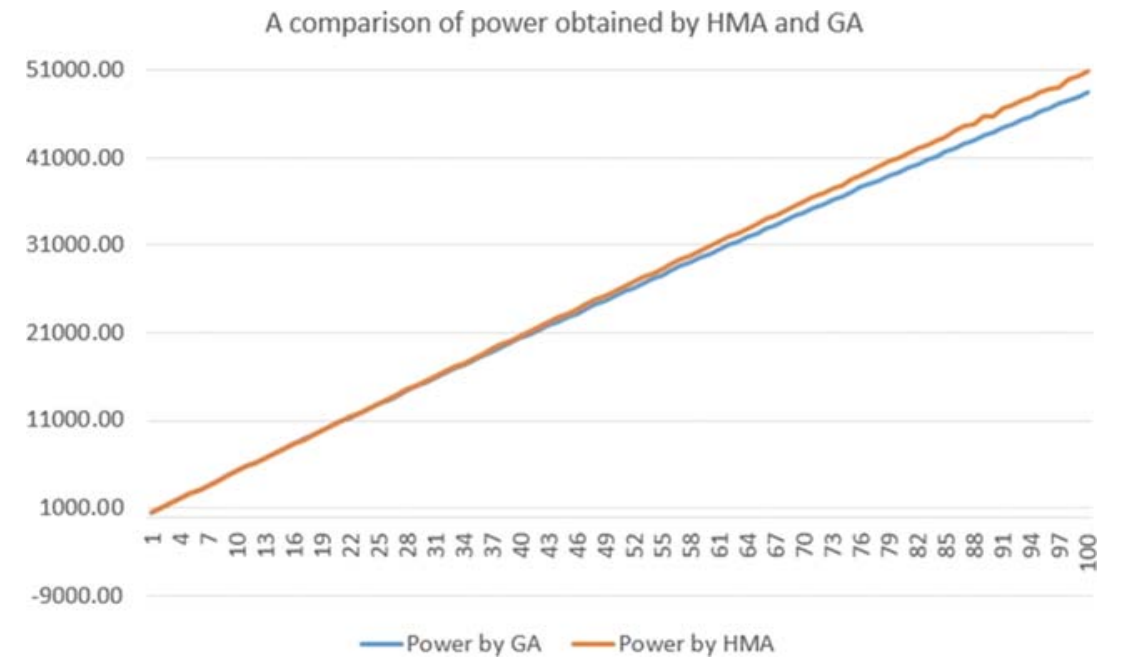

FIG. 2. COMPARISON OF POWER BY HMA AND GA

A comparison of the cost from HMA and GA

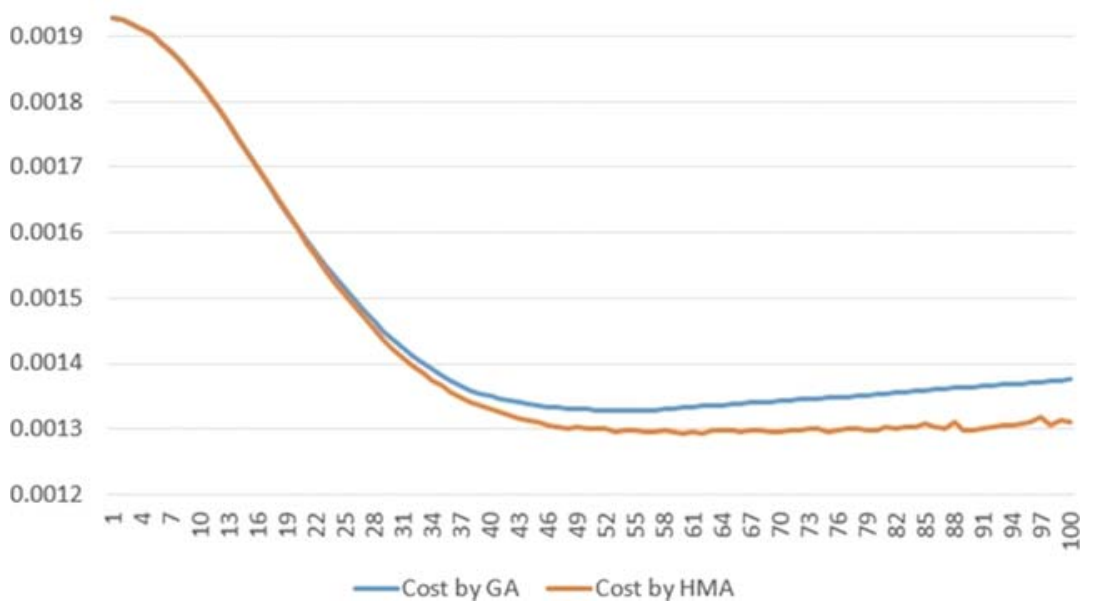

FIG. 3. COMPARISON OF COST BY HMA AND GA 
However, the supremacy of the HMA is established at the installation of the $20^{\text {th }}$ turbine and continues till the installation of the $100^{\text {th }}$ turbine.

At the installation of the $20^{\text {th }}$ turbine the HMA takes the lead and posts results of cost at 0.0016075 whereas the GA lags at a cost of 0.0016091 . Thus, the HMA is keeps its supremacy till the time the $100^{\text {th }}$ turbine is installed with a result of cost valued at 0.0013111 and the GA lags with a result of 0.0013759 .

The lowest cost is reported by GA [2] at a total of $54^{\text {th }}$ turbines at a value of 0.0013292. However, using HMA it is the lowest cost is reported when $60^{\text {th }}$ turbines are installed at a value of 0.0012941 .

In Table 1, it is clearly evident that a higher amount of peak power is produced with a higher number of turbines at a considerably lower cost as compared to the GA [2].

In Table 2, It is evident that the highest amount of power is produced by HMA as compared to GA [2] and Mosetti et. al. [13].

Similarly in Table 3, when we compare the results obtained by Grady et. al. [16], Rajper and Amin by using GA [2] and by HMA it is evident that the latter is the best algorithm for evaluation of the objective function.

In Table 4, the results of Marmidis et. l. [18], GA [2] and the HMA clearly suggest that, from these three techniques, HMA is the better technique for Wind Turbine Micrositing.

Finally, in Table 5, the results of Mittal [3], Rajper and Amin (GA) [2] and HMA can be compared and it is evident that HMA is the better technique.

The results tabulated in Table $\mathbf{6}$ shows the results for turbine numbers 1-100 as obtained by the application of the HMA. It is evident that the HMA is better than the GA technique [2].
It was demonstrated that the optimal number of turbines that can be installed by using the HMA is 68 on a square grid of 2x2 km area.

TABLE 1. PEAK COST TO POWER RATIO, GA [2] AND HMA

\begin{tabular}{|c|c|c|}
\hline & By using GA [2] & By using HMA \\
\hline Number of Turbines & 54 & 60 \\
\hline Peak Power produced & $27,169.52$ & $30,939.78$ \\
\hline Cost per unit power & 0.0013292 & 0.0012941 \\
\hline
\end{tabular}

TABLE 2. MOSETTI [13], GA [2] AND HMA

\begin{tabular}{|c|c|c|c|}
\hline & $\begin{array}{c}\text { Mosettiet. al. } \\
\text { [13] }\end{array}$ & $\begin{array}{c}\text { By using GA } \\
{[2]}\end{array}$ & $\begin{array}{c}\text { By using } \\
\text { HMA }\end{array}$ \\
\hline Number of Turbines & 26 & 26 & 26 \\
\hline $\begin{array}{c}\text { Peak Power produced } \\
\text { Objective function } \\
\text { value }\end{array}$ & 12,352 & $13,364.16$ & $13,459.11$ \\
\hline Efficiency & $91.645 \%$ & $99.152 \%$ & $99.6 \%$ \\
\hline
\end{tabular}

TABLE 3. GRADY ET AL. [16] GA [2] AND HMA

\begin{tabular}{|c|c|c|c|}
\hline & $\begin{array}{c}\text { Gradyet. al. } \\
{[16]}\end{array}$ & $\begin{array}{c}\text { By using GA } \\
{[2]}\end{array}$ & $\begin{array}{c}\text { By using } \\
\text { HMA }\end{array}$ \\
\hline Number of Turbines & 30 & 30 & 30 \\
\hline $\begin{array}{c}\text { Peak Power produced } \\
\text { Objective function } \\
\text { value }\end{array}$ & $14,310.00$ & $15,372.49$ & $15,528.06$ \\
\hline Efficiency & 92.0015436 & 0.001423 & 0.0014225 \\
\hline
\end{tabular}

TABLE 4. MARMIDIS, ET, AL. [18] , GA [2] AND HMA

\begin{tabular}{|c|c|c|c|}
\hline & $\begin{array}{c}\text { Marmidis, et. al. } \\
\text { [18] }\end{array}$ & $\begin{array}{c}\text { By using GA } \\
\text { [2] }\end{array}$ & $\begin{array}{c}\text { By using } \\
\text { HMA }\end{array}$ \\
\hline Number of Turbines & 32 & 32 & 32 \\
\hline $\begin{array}{c}\text { Peak Power produced } \\
\text { Objective function } \\
\text { value }\end{array}$ & 0.0014107 & 0.001423 & 0.0013957 \\
\hline Efficiency & Not reported & $98.721 \%$ & $99.9 \%$ \\
\hline
\end{tabular}

TABLE 5. MITTAL, ET. AL. [3] GA [2] AND HMA

\begin{tabular}{|c|c|c|c|}
\hline & $\begin{array}{c}\text { Mittalet. al. [ } \\
\text { 3] }\end{array}$ & $\begin{array}{c}\text { By using GA } \\
\text { [2] }\end{array}$ & $\begin{array}{c}\text { By using } \\
\text { HMA }\end{array}$ \\
\hline Number of Turbines & 44 & 44 & 44 \\
\hline Peak Power produced & $21,936.00$ & $22,306.78$ & $22,738.14$ \\
\hline $\begin{array}{c}\text { Objective function } \\
\text { value } \\
\text { (Using GA or HMA) }\end{array}$ & 0.0013602 & 0.001423 & 0.0013123 \\
\hline Efficiency & $96.1 \%$ & $97.79 \%$ & $99.69 \%$ \\
\hline
\end{tabular}

Mehran University Research Journal of Engineering \& Technology, Volume 36, No. 3, July, 2017 [p-ISSN: 0254-7821, e-ISSN: 2413-7219] 
A New Hybrid Metaheuristic Algorithm for Wind Farm Micrositing

TABLE 6. SHOWS THE COMPARISON OF THE HMA AND THE GA WITH RESPECT TO THE TOTAL POWER GENERATED AND THE COST PER UNIT POWER

\begin{tabular}{|c|c|c|c|c|c|}
\hline No. & Power by GA & Power by HMA & Cost by GA & Cost by HMA & Efficiency by HMA \\
\hline 1. & 518.4 & 518.4 & 0.0019279 & 0.0019279 & 1 \\
\hline 2. & $1,036.80$ & $1,036.80$ & 0.0019246 & 0.0019246 & 1 \\
\hline 3. & $1,555.20$ & $1,555.20$ & 0.001919 & 0.001919 & 1 \\
\hline 4. & $2,073.60$ & $2,073.60$ & 0.0019114 & 0.0019114 & 1 \\
\hline 5. & $2,592.00$ & $2,592.00$ & 0.0019016 & 0.0019016 & 1 \\
\hline 6. & $3,110.40$ & $3,110.40$ & 0.00189 & 0.00189 & 1 \\
\hline 7. & $3,628.80$ & $3,628.80$ & 0.0018765 & 0.0018765 & 1 \\
\hline 8. & $4,147.20$ & $4,147.20$ & 0.0018613 & 0.0018613 & 1 \\
\hline 9. & $4,665.60$ & $4,665.60$ & 0.0018445 & 0.0018445 & 1 \\
\hline 10. & $5,184.00$ & $5,183.99$ & 0.0018263 & 0.0018263 & 1 \\
\hline 11. & $5,702.40$ & $5,702.40$ & 0.0018069 & 0.0018069 & 1 \\
\hline 12. & $6,220.80$ & $6,220.80$ & 0.0017865 & 0.0017865 & 1 \\
\hline 13. & $6,739.20$ & $6,739.20$ & 0.0017652 & 0.0017652 & 1 \\
\hline 14. & $7,257.60$ & $7,257.60$ & 0.0017432 & 0.0017432 & 1 \\
\hline 15. & $7,776.00$ & $7,776.00$ & 0.0017207 & 0.0017207 & 1 \\
\hline 16. & $8,294.40$ & $8,293.74$ & 0.0016979 & 0.001698 & 0.9999 \\
\hline 17. & $8,812.80$ & $8,811.82$ & 0.0016749 & 0.0016751 & 0.9999 \\
\hline 18. & $9,331.20$ & $9,328.15$ & 0.0016519 & 0.0016525 & 0.9996 \\
\hline 19. & $9,849.60$ & $9,845.33$ & 0.0016291 & 0.0016298 & 0.9996 \\
\hline 20. & $10,351.68$ & $10,361.76$ & 0.0016091 & 0.0016075 & 0.9994 \\
\hline 21. & $10,853.76$ & $10,879.74$ & 0.0015893 & 0.0015855 & 0.9994 \\
\hline 22. & $11,355.84$ & $11,397.14$ & 0.0015697 & 0.0015641 & 0.9993 \\
\hline 23. & $11,857.92$ & $11,914.73$ & 0.0015506 & 0.0015432 & 0.9993 \\
\hline 24. & $12,360.00$ & $12,431.28$ & 0.0015321 & 0.0015233 & 0.9992 \\
\hline 25. & $12,862.08$ & $12,947.21$ & 0.0015142 & 0.0015042 & 0.999 \\
\hline 26. & $13,364.16$ & $13,459.11$ & 0.001497 & 0.0014865 & 0.9986 \\
\hline 27. & $13,866.24$ & $13,982.48$ & 0.0014807 & 0.0014684 & 0.999 \\
\hline 28. & $14,368.32$ & $14,501.61$ & 0.0014652 & 0.0014517 & 0.9991 \\
\hline 29. & $14,870.41$ & $15,013.67$ & 0.0014506 & 0.0014367 & 0.9987 \\
\hline 30. & $15,372.49$ & $15,528.06$ & 0.0014369 & 0.0014225 & 0.9985 \\
\hline 31. & $15,874.57$ & $16,039.80$ & 0.0014241 & 0.0014095 & 0.9981 \\
\hline 32. & $16,376.65$ & $16,571.59$ & 0.0014123 & 0.0013957 & 0.999 \\
\hline 33. & $16,878.73$ & $17,069.71$ & 0.0014014 & 0.0013857 & 0.9978 \\
\hline 34. & $17,380.81$ & $17,580.91$ & 0.0013914 & 0.0013749 & 0.9979 \\
\hline 35. & $17,882.89$ & $18,104.82$ & 0.0013822 & 0.0013653 & 0.9978 \\
\hline 36. & $18,384.97$ & $18,621.28$ & 0.0013739 & 0.0013564 & 0.9978 \\
\hline 37. & $18,887.05$ & $19,138.79$ & 0.0013663 & 0.0013483 & 0.9978 \\
\hline 38. & $19,389.13$ & $19,657.24$ & 0.0013595 & 0.001341 & 0.9979 \\
\hline 39. & $19,875.40$ & $20,152.64$ & 0.0013545 & 0.0013359 & 0.9968 \\
\hline 40. & $20,361.68$ & $20,667.59$ & 0.0013501 & 0.0013301 & 0.9967 \\
\hline 41. & $20,847.95$ & $21,182.79$ & 0.0013463 & 0.001325 & 0.9966 \\
\hline 42. & $21,334.23$ & $21,691.27$ & 0.0013429 & 0.0013208 & 0.9963 \\
\hline 43. & $21,820.50$ & $22,215.67$ & 0.0013401 & 0.0013162 & 0.9966 \\
\hline 44. & $22,306.78$ & $22,738.14$ & 0.0013376 & 0.0013123 & 0.9969 \\
\hline 45. & $22,793.05$ & $23,222.92$ & 0.0013356 & 0.0013109 & 0.9955 \\
\hline 46. & $23,279.33$ & $23,779.96$ & 0.0013339 & 0.0013058 & 0.9972 \\
\hline 47. & $23,765.60$ & $24,280.28$ & 0.0013325 & 0.0013043 & 0.9965 \\
\hline 48. & $24,251.87$ & $24,801.96$ & 0.0013315 & 0.0013019 & 0.9967 \\
\hline 49. & $24,738.15$ & $25,264.49$ & 0.0013306 & 0.0013029 & 0.9946 \\
\hline 50. & $25,224.42$ & $25,788.40$ & 0.00133 & 0.0013009 & 0.9949 \\
\hline
\end{tabular}

Mehran University Research Journal of Engineering \& Technology, Volume 36, No. 3, July, 2017 [p-ISSN: 0254-7821, e-ISSN: 2413-7219] 
A New Hybrid Metaheuristic Algorithm for Wind Farm Micrositing

\begin{tabular}{|c|c|c|c|c|c|}
\hline No. & Power by GA & Power by HMA & Cost by GA & Cost by HMA & Efficiency by HMA \\
\hline 51. & $25,710.70$ & $26,278.15$ & 0.0013296 & 0.0013009 & 0.9939 \\
\hline 52. & $26,196.97$ & $26,796.18$ & 0.0013293 & 0.0012996 & 0.994 \\
\hline 53. & $26,683.25$ & $27,363.99$ & 0.0013292 & 0.0012961 & 0.996 \\
\hline 54. & $27,169.52$ & $27,817.18$ & 0.0013292 & 0.0012982 & 0.9937 \\
\hline 55. & $27,655.80$ & $28,339.58$ & 0.0013293 & 0.0012972 & 0.994 \\
\hline 56. & $28,142.07$ & $28,850.52$ & 0.0013294 & 0.0012968 & 0.9938 \\
\hline 57. & $28,628.34$ & $29,404.11$ & 0.0013297 & 0.0012946 & 0.9951 \\
\hline 58. & $29,099.31$ & $29,815.36$ & 0.0013307 & 0.0012987 & 0.9916 \\
\hline 59. & $29,570.28$ & $30,414.50$ & 0.0013317 & 0.0012948 & 0.9944 \\
\hline 60. & $30,041.24$ & $30,939.78$ & 0.0013328 & 0.0012941 & 0.9947 \\
\hline 61. & $30,512.21$ & $31,409.71$ & 0.0013338 & 0.0012957 & 0.9933 \\
\hline 62. & $30,983.17$ & $31,951.69$ & 0.0013349 & 0.0012944 & 0.9941 \\
\hline 63. & $31,454.14$ & $32,395.18$ & 0.0013359 & 0.0012971 & 0.9919 \\
\hline 64. & $31,925.11$ & $32,856.39$ & 0.001337 & 0.0012991 & 0.9903 \\
\hline 65. & $32,396.07$ & $33,412.45$ & 0.001338 & 0.0012973 & 0.9916 \\
\hline 66. & $32,867.04$ & $33,938.34$ & 0.0013391 & 0.0012968 & 0.9919 \\
\hline 67. & $33,338.00$ & $34,440.55$ & 0.0013401 & 0.0012972 & 0.9916 \\
\hline 68. & $33,808.97$ & $34,910.67$ & 0.0013411 & 0.0012988 & 0.9903 \\
\hline 69. & $34,279.94$ & $35,475.32$ & 0.0013421 & 0.0012968 & 0.9918 \\
\hline 70. & $34,750.90$ & $36,033.64$ & 0.001343 & 0.0012952 & 0.993 \\
\hline 71. & $35,221.87$ & $36,480.02$ & 0.001344 & 0.0012976 & 0.9911 \\
\hline 72. & $35,692.83$ & $36,942.85$ & 0.0013449 & 0.0012994 & 0.9898 \\
\hline 72. & $35,692.83$ & $36,942.85$ & 0.0013449 & 0.0012994 & 0.9898 \\
\hline 73. & $36,163.80$ & $37,448.44$ & 0.0013458 & 0.0012996 & 0.9896 \\
\hline 74. & $36,634.76$ & $37,932.91$ & 0.0013467 & 0.0013006 & 0.9888 \\
\hline 75. & $37,105.73$ & $38,594.51$ & 0.0013475 & 0.0012956 & 0.9927 \\
\hline 76. & $37,576.70$ & $38,991.64$ & 0.0013484 & 0.0012995 & 0.9897 \\
\hline 77. & $38,032.84$ & $39,426.54$ & 0.0013497 & 0.001302 & 0.9877 \\
\hline 78. & $38,488.98$ & $39,967.44$ & 0.0013511 & 0.0013011 & 0.9884 \\
\hline 79. & $38,945.12$ & $40,580.13$ & 0.0013523 & 0.0012979 & 0.9909 \\
\hline 80. & $39,401.26$ & $41,041.24$ & 0.0013536 & 0.0012995 & 0.9896 \\
\hline 81. & $39,857.40$ & $41,454.70$ & 0.0013548 & 0.0013026 & 0.9872 \\
\hline 82. & $40,313.54$ & $42,005.19$ & 0.001356 & 0.0013014 & 0.9882 \\
\hline 83. & $40,769.68$ & $42,445.11$ & 0.0013572 & 0.0013036 & 0.9865 \\
\hline 84. & $41,225.82$ & $42,948.53$ & 0.0013584 & 0.0013039 & 0.9863 \\
\hline 85. & $41,681.96$ & $43,334.30$ & 0.0013595 & 0.0013077 & 0.9834 \\
\hline 86. & $42,138.10$ & $43,993.24$ & 0.0013606 & 0.0013032 & 0.9868 \\
\hline 87. & $42,594.24$ & $44,556.76$ & 0.0013617 & 0.0013017 & 0.9879 \\
\hline 88. & $43,050.38$ & $44,729.76$ & 0.0013627 & 0.0013116 & 0.9805 \\
\hline 89. & $43,506.51$ & $45,675.66$ & 0.0013638 & 0.001299 & 0.9899 \\
\hline 90. & $43,962.65$ & $45,675.66$ & 0.0013648 & 0.0012982 & 0.9906 \\
\hline 91. & $44,418.79$ & $46,597.23$ & 0.0013658 & 0.0013019 & 0.9878 \\
\hline 92. & $44,874.93$ & $47,096.77$ & 0.0013668 & 0.0013023 & 0.9875 \\
\hline 93. & $45,331.07$ & $47,505.37$ & 0.0013677 & 0.0013051 & 0.9854 \\
\hline 94. & $45,787.21$ & $47,995.51$ & 0.0013687 & 0.0013056 & 0.9849 \\
\hline 95. & $46,243.35$ & $48,392.71$ & 0.0013696 & 0.0013087 & 0.9826 \\
\hline 96. & $46,685.14$ & $48,775.76$ & 0.0013709 & 0.0013121 & 0.9801 \\
\hline 97. & $47,126.92$ & $49,088.18$ & 0.0013722 & 0.0013174 & 0.9762 \\
\hline 98. & $47,568.70$ & $49,988.54$ & 0.0013735 & 0.001307 & 0.984 \\
\hline 99. & $48,010.48$ & $50,298.80$ & 0.0013747 & 0.0013122 & 0.9801 \\
\hline 100. & $48,452.26$ & $50,846.92$ & 0.0013759 & 0.0013111 & 0.9808 \\
\hline
\end{tabular}

Mehran University Research Journal of Engineering \& Technology, Volume 36, No. 3, July, 2017 [p-ISSN: 0254-7821, e-ISSN: 2413-7219] 


\section{CONCLUSIONS}

The algorithm implementation shows the comparison with the use of a single algorithm i.e. the GA and it shows that the HMA performs better.

This implementation is a significant step in towards learning the behavior of algorithms and their added advantages by using them together.

The main contribution of this work is that, the FA and the DEA have been used for the first time in tandem. This adds to a significant contribution by implementation of the both algorithms and the addition of complexity to the WTO problem.

This study has successfully calculated the total energy produced by a wind farm by using a HMA and compared it with the past approaches of using single algorithms. It is shown that there is a significant advantage of using the HMA as compared to the use of single algorithms.

\section{ACKNOWLEDGMENTS}

The authors would like to thank Prof. Naeem-ul-Hassan Janjua, Islam College of Engineering, Sialkot, for his technical help, Dr. Riazuddin Abro, Pakistan Council of Scientific \& Industrial Research, for his sincere advice and Prof. Hafiz Abdul Ghani Shaikh, University of Sindh, Jamshoro, Pakistan, for spiritual guidance, for the writing of this script.

\section{REFERENCES}

Massan, S.-R., Wagan, A.I., Shaikh, M.M., and Abro, R., "Wind Turbine Micrositing by Using the Firefly Algorithm”,Applied Soft Computing, Volume 27, pp. 450-456, November, 2015.

Rajper, S., and Amin, I.J., "Optimization of Wind Turbine Micrositing: A Comparative Study”, Renewable and Sustainable Energy Reviews, Volume 16, pp. 5485-5492, 2012

Mittal, A., "Optimization of the Layout of Large Wind Farms using Genetic Algorithm”, MS Thesis, Department of Aerospace and Mechanical Engineering, Case Western Reserve University, USA, 2010.
[4]

Wan, C., Wang, J., Yang, G., Gu, H., and Zhang, X., "Wind Farm Micro-Siting by Gaussian Particle Swarm Optimization with Local Search Strategy",Renewable Energy, Volume 48, No. C, pp. 276-286, 2012.

[5] Wan, C., Wang, J., Yang, G., and Zhang, X., "Particle Swarm Optimization Based on Gaussian Mutation and its Application to Wind Farm Micro-Siting”,49th IEEE Conference on Decision and Control (CDC), pp. 2227-2232, July, 2015.

[6] Ting, T.O., Yang, X.-S., Cheng, S., and Huang, K., "Hybrid Metaheuristic Algorithms: Past, Present, and Future”, Studies in Computational Intelligence, Volume 585, pp. 71-83, 2015.

[7] Barnett, G.L., Funke, S.W., and Piggott, M.D., "Hybrid Global-Local Optimisation Algorithms for the Layout Design of Tidal Turbine Arrays", arXiv:1410.2476v1 [math.OC], pp. 1-36, $9^{\text {th }}$ October, 2014.

[8] Tesauro, A., Rethore, P.-E., and Larsen, G.C., "State of the Art of Wind Farm Optimization”, European Wind Energy Conference \& Exhibition, pp. 1-11, 2012.

[9] Kusiak, A., and Song, Z., "Design of Wind Farm Layout for Maximum Wind Energy Capture”,Renewable Energy, Volume 35, No. 3, pp. 685-694, March, 2010.

[10] Funke, S.W., and Team, “OpenTidalFarm”,2014. [Online. Available: http://opentidalfarm.readthedocs.org/

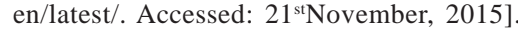

[11] Ryanking, “OpenWindFarm”,2015. [Online. Available: https://github.com/ryannking/OpenWindFarm. Accessed: 25th November, 2015].

[12] Massan, S.-R., Wagan, A.I., and Shaikh, M.M., "Power Optimization of Wind Turbines by the Adjoint Method”, Sindh University Research Journal (Science Series), Volume 48, No. 3, pp. 559-562, Jamshoro, Pakistan, 2016.

[13] Mosetti, G., Poloni, C., and Diviacco, B., "Optimization of Wind Farms Positioning in Large Wind Farms by Means of a Genetic Algorithm”,Wind Engineering and Industrial Aerodynamics, No. 51, pp. 105-116, 1994.

[14] Beyer,"Optimization of Wind Farm Configurations with Variable Number of Turbines", Proceedings of European Union Wind Energy Conference, Göteborg, pp. 1073-1076, May, 1996.

[15] Barthelmie, R., Pryor, S., Frandsen, S., and Larsen, S., "Analytical Modelling of Large Wind Clusters", Proceedings of Special Topic Conference: The Science of Making Torque from Wind, Delft, pp. 292-303, April, 2004. 
[16] Grady, S.A., Hussaini, M.Y., and Abdullah, M.M., "Placement of Wind Turbines using Genetic Algorithms", Renewable Energy, Volume 1, No. 30, pp. 259-270, 2005.

[17] Wan, C., Wang, J., Yang, G., and Zhang, X., “Optimal Siting of Wind Turbines using Real Coded Genetic Algorithms”,National High Technology Research and Development Program in China, 2007.

[18] Marmidis, G., Lazarou, S., and Pyrgioti, E., "Optimal Placement of Wind Turbines in a Wind Park using Monte Carlo Simulation”, Renewable Energy, No. 33, pp. 1455-1460, 2008.

[19] Jos'e-Francisco, H.-A., Valenzuela-Rend'on, M., Oliver, P.-O., and Jorge-Rodolfo, F.-A., "Linear Wind Farm Layout Optimization through Computational Intelligence”, Instituto Tecnol'ogico y de Estudios Superiores de Monterrey, Campus Monterrey, Eugenio Garza Sada 2501 Sur, Monterrey, N.L., M’exico, CP 64849, 2009.

[20] Kusiak, A., and Haiyang, Z., "Optimization of Wind Turbine Energy and Power Factor with an Evolutionary Computation Algorithm”, Energy, Volume 35, pp. 1324-1332, 2010.

[21] Palmaa, J.M.L.M., Castro, F.A., Ribeiro, L.F., Rodrigues, A.H., and Pinto, A.P., "Linear and Nonlinear Models Inwind Resource Assessment and Wind Turbine MicroSiting in Complex Terrain”,Journal of Wind Engineering and Industrial Aerodynamics, Volume 96, pp. 2308-2326, 2008.

[22] Wan, C., Wang, J., Yang, G., Li, X., and Zhang, X., "Optimal Micro-Siting of Wind Turbines by Genetic Algorithms Based on Improved Wind and Turbine Models", Proceedings of IEEE 48th Chinese Conference on Decision and Control, pp. 5092-5096, December, 2009.

[23] Emami, A., and Nougreh, P., "New Approach on Optimization in Placement of Wind Turbines within Wind Farm by Genetic Algorithms”, Renewable Energy, No. 35, pp. 169-178, 2010.

[24] Rasuo, B.P., and Bengin, A.C., "Optimization of Wind Farm Layout”, FME Transactions, Volume 38, No. 3, pp 107-114, 2010.
[25] Lazarou, S., Vita, V., and Ekonomou, L., “Application of Powell's Optimisation Method for the Optimal Number of Wind Turbines in a Wind Farm”, Science, Measurement \& Technology, Volume IET 5, No. 3, pp. 77-80, 2011

[26] Mora, J.S., Gonza'lez, J.C., Santos, J.R., Payan, M.B., and Rodriguez, A.G.G., "Optimization of Wind Farm Turbines Layout using an Evolutive Algorithm”, Renewable Energy, Volume 35, No. 8, pp. 1671-1681, 2010.

[27] González, J.S., Payán, M.B., Santos, J.M.R., and González-Longatt, F., “A Review and Recent Developments in the Optimal Wind-Turbine MicroSiting Problem”, Renewable and Sustainable Energy Reviews, No. 30, pp. 133-144, 2014.

[28] Glover, F., "Future Paths for Integer Programming and Links to Artificial Intelligence”, Computers and Operations Research, Volume 13, No. 5, pp. 533-549, 1986.

[29] Karampelas, P., Ekonomou, L., Fotis, G.P., and Vita, V., "Evaluation of the Optimal Number of Wind Turbines in a Wind Farm Using the Downhill Simplex Optimization Method”, International Journal on Power System Optimization, Volume 3, No. 1, pp. 11-14, 2011.

[30] Ituarte-Villarreal, C.M., and Espiritu, J.F., “Optimization of Wind Turbine Placement using a Viral Based Optimization Algorithm”, Procedia Computer Science, Volume 6, pp. 469-474, 2011.

[31] Chowdhury, S., Zhang, J., Messac, A., and Castillo, L., "Unrestricted WInd Farm Layout Optimization (UWFLO): Investigating Key Factors Influencing the Maximum Power Generation”, Renewable Energy, Volume 38, No. 1, pp. 16-30, 2012.

[32] Song, M.X., Chen, K., He, Z.Y., and Zhang, X., "Wake Flow Model of Wind Turbine using Particle Simulation” ,Renewable Energy, Volume 41, pp. 185-190, 2012.

[33] Jensen, N.O., “A Note on Wind Generator Interaction”, RISO-M-2411, 1983. 
[34] Song, M.X., Chen, K., He, Z.Y., and Zhang, X., "Optimization of Wind Farm Micro-Siting for Complex Terrain using Greedy Algorithm”, Energy, Volume 67, pp. 454-459, 2014.

[35] Rehmani, R., Khairuddin, A., Cherati, S.M., and Pesaran, M.H.A., “A Novel Method for Optimal Placing Wind Turbines in a Wind Farm Using Particle Swarm Optimization (PSO)”, Proceedings of IEEE Conference on IPEC, pp. 134-139, 2010.

[36] Chen, Y., Li, H., Jin, K., and Song, Q., "Wind Farm Layout Optimization using Genetic Algorithm with Different Hub Height Wind Turbines”, Energy Conversion and Management, Volume 70, pp. 56-65, June, 2013.

[37] Gaumond, M., Réthoré, P.E., Bechmann, A., Ott, S., Larsen, G.C., Pena Diaz, A., and Kurt, K.S., "Benchmarking of Wind Turbine Wake Models in Large Offshore Windfarms”, Proceedings of Science of Making Torque from Wind, pp. 10-16, 2012.

[38] Rao, A.R.M., and Shyju, P.P., "Development of a Hybrid Meta-Heuristic Algorithm for Combinatorial Optimisation and its Application for Optimal Design of Laminated Composite Cylindrical Skirt”, Computers and Structures, Volume 86, No. 7-8, pp. 796-815, 2008.

[39] Salcedo-Sanz, S., Xu, Y., and Yao, X., "Hybrid MetaHeuristics Algorithms for Task Assignment in Heterogeneous Computing Systems”, Computers and Operations Research, Volume 33, No. 3, pp. 820-835, 2006.

[40] Shahsavari-Pour, N., and Ghasemishabankareh, B., “A Novel Hybrid Meta-Heuristic Algorithm for Solving Multi Objective Flexible Job Shop Scheduling”, Journal of Manufacturing Systems, Volume 32, No. 4, pp. 771-780, 2013.

[41] Lozano, M., and García-Martínez, C., "Hybrid Metaheuristics with Evolutionary Algorithms Specializing in Intensification and Diversification: Overview and Progress Report”, Computers and Operations Research, Volume 37, No. 3, pp. 481-497, 2010.

[42] Leung, S.C.H., Zhang, D., Zhou, C., and Wu, T., “A Hybrid Simulated Annealing Metaheuristic Algorithm for the Two-Dimensional Knapsack Packing Problem”, Computers and Operations Research, Volume 39, No. 1, pp. 64-73, 2012.

[43] Poorzahedy, H., and Rouhani, O.M., "Hybrid MetaHeuristic Algorithms for Solving Network Design Problem”, European Journal of Operational Research, Volume 182, No. 2, pp. 578-596, 2007.
Yi, H., Duan, Q., and Liao, T.W., "Three Improved Hybrid Metaheuristic Algorithms for Engineering Design Optimization”, Applied Soft Computing Journal, Volume 13, No. 5, pp. 2433-2444, 2013.

[45] Fattahi, P., Hajipour, V., and Nobari, A., "A Bi-Objective Continuous Review Inventory Control Model: ParetoBased Meta-Heuristic Algorithms", Applied Soft Computing, Volume 32, pp. 211-223, 2015.

[46] Massan, S.-R., Wagan, A.I., Shaikh, M.M., and Shah, M.S., "Application of Differential Evolution Algorithm for Wind Turbine Micrositing”, Mehran University Research Journal of Engineering \& Technology, Volume 36, No. 2, pp. 353-366, Jamshoro, Pakistan, April, 2017.

[47] Betz, A., “Betz's Law”, [Online. Available: http:// en.wikipedia.org/wiki/Betz'_law] pp. 1, 2016 (Accessed on 1st November, 2016)

[48] Wikipedia, "Wind Turbine Aerodynamics - Axial Induction Facto", 2016. [Online. Available: https:// en.wikipedia.org/wiki/Wind-turbine_aerodynamics. Accessed: 20th September, 2016].

[49] Wikipedia, "Differential Evolution Algorithm”,2014. [Online. Available: http://en.wikipedia.org/wiki/ Differential_evolution. Accessed: 27th July, 2014].

[50] Lee, J.B., "Clever Algorithms - Nature Inspired Programming Recipes”, Melbourne, 2011.

[51] Teo, J., "Exploring Dynamic Self-Adaptive Populations in Differential Evolution”, Soft Computing, No. 10, pp. 673-686, 2006.

[52] Yang, X.-S., "Firefly Algorithms for Multimodal Optimization”,Stochastic Algorithms: Foundations and Applications, pp. 169-178, 2009.

[53] Yang, X.-S., "Firefly Algorithm, Stochastic Test Functions and Design Optimisation”, International Journal of Bio-Inspired Computation, pp. 1-12, 2010.

[54] Wikipedia, “Firefly Algorithm”, 2014. [Online. Available: http://en.wikipedia.org/wiki/Firefly_algorithm. Accessed27th July, 2014].

[55] Yang, X.-S., "Firefly Algorithm, Levy Flights and Global Optimization”, International Journal of Bio-Inspired Computation, 2010.

[56] Yang, X.-S., "Introduction to Computational Mathematics”, 2 ${ }^{\text {nd }}$ Edition, World Scientific, 2014.

[57] Zachariadis, E.E., Tarantilis, C.D., and Kiranoudis, C.T., "A Hybrid Metaheuristic Algorithm for the Vehicle Routing Problem with Simultaneous Delivery and PickUp Service”,Expert Systems with Applications, Volume 36, No. 2, pp. 1070-1081, March, 2009. 